\title{
Lipid Levels and Renal Function Decline in Pre-Dialysis Patients
}

\author{
Moniek C.M. de Goeij ${ }^{a} \quad$ Joris I. Rotmans ${ }^{b} \quad$ Xanthe Matthijssen $^{a}$ \\ Dinanda J. de Jager ${ }^{a}$ Friedo W. Dekker ${ }^{a}$ Nynke Halbesma ${ }^{a, c}$ \\ for the PREPARE-2 Study Group

\begin{abstract}
Departments of a Clinical Epidemiology and ${ }^{\mathrm{b}}$ Nephrology, Leiden University Medical Center, Leiden, The Netherlands; ${ }^{c}$ Centre for Population Health Sciences, University of Edinburgh, Edinburgh, UK
\end{abstract}

\section{Key Words}

CKD stages IV-V $\cdot$ Pre-dialysis care $\cdot$ Lipids $\cdot$ Renal function decline $\cdot$ Statin $\cdot$ Fibrate

\begin{abstract}
Background: Little is known about the effect of low-density lipoprotein (LDL) cholesterol, triglyceride (TG), and high-density lipoprotein (HDL) cholesterol levels on renal function decline in patients receiving specialized pre-dialysis care. Methods: In the prospective PREPARE-2 study, incident patients starting pre-dialysis care were included when referred to one of the 25 participating Dutch specialized pre-dialysis outpatient clinics (2004-2011). Clinical and laboratory data were collected every 6 months. A linear mixed model was used to compare renal function decline between patients with LDL cholesterol, TG, or HDL cholesterol levels above and below the target goals (LDL cholesterol: $<2.50 \mathrm{mmol} / \mathrm{l}, \mathrm{TG}:<2.25 \mathrm{mmol} / \mathrm{l}$, and HDL cholesterol: $\geq 1.00 \mathrm{mmol} / \mathrm{l})$. Additionally the HDL/LDL cholesterol ratio was investigated ( $\geq 0.4)$. Results: In our study population $(n=306)$, the median age was 69 years and $70 \%$ were male. Patients with LDL cholesterol levels above the target of $2.50 \mathrm{mmol} / \mathrm{l}$ experienced an accelerated renal function decline compared to patients with levels below the target (crude additional decline: $0.10 \mathrm{ml} / \mathrm{min} / 1.73 \mathrm{~m}^{2} / \mathrm{month}, 95 \%$ CI 0.00-0.20; $\left.\mathrm{p}<0.05\right)$. A similar trend was found for TG levels above the target of $2.25 \mathrm{mmol} / \mathrm{l}\left(0.05 \mathrm{ml} / \mathrm{min} / 1.73 \mathrm{~m}^{2} / \mathrm{month}, 95 \% \mathrm{CI}-0.06\right.$ to 0.16$)$ and for a HDL/LDL cholesterol ratio below $0.4\left(0.06 \mathrm{ml} / \mathrm{min} / 1.73 \mathrm{~m}^{2} / \mathrm{month}, 95 \% \mathrm{CI}\right.$ -0.05 to 0.18 ). Adjustment for potential confounders resulted in similar results, and the exclusion of patients who were prescribed lipid-lowering medication (statin, fibrate, or cholesterol absorption inhibitor) resulted in a slightly larger estimated effect. Conclusion: High levels of LDL cholesterol were associated with an accelerated renal function decline, independent of the prescription of lipid-lowering medication.




\section{Introduction}

In the general population, it is known that abnormal lipid levels, i.e. high low-density lipoprotein (LDL) cholesterol, high triglycerides (TG), and low high-density lipoprotein (HDL) cholesterol levels, are associated with higher cardiovascular mortality [1-3]. For patients on dialysis treatment, the association of abnormal lipid levels with all-cause and cardiovascular mortality is different compared with the general population. Having abnormal lipid levels (especially high total cholesterol) seems to have a beneficial effect in these patients, associated with lower risks of mortality [4-6]. Studies investigating the association of abnormal lipid levels with all-cause and cardiovascular mortality in chronic kidney disease (CKD) patients not on dialysis [7-9] showed no or a slightly reversed association. However, this reversed association was again mainly observed for total cholesterol levels, which is a combination of 'good' and 'bad' lipids. Moreover, low cholesterol levels may be a consequence of inflammatory processes $[10,11]$. Besides this, a subgroup analysis of a large trial showed that a lipid-lowering combination therapy of a statin plus cholesterol absorption inhibitor, both LDL cholesterol-lowering medications, decreased the risk of major cardiovascular events (including cardiovascular mortality) in pre-dialysis patients [12]. Primarily based on the results from this trial, lipid-lowering medication is recommended to pre-dialysis patients for preventing cardiovascular complications. Is there also enough evidence available for renal function decline, another important clinical outcome?

In the general population, several studies found a possible association of abnormal lipid levels with an accelerated renal function decline [13-16]. This association seems comparable in patients with $\mathrm{CKD}$, in whom abnormal lipid levels are associated with a faster disease progression [17-21]. However, these studies mainly focused on total cholesterol levels in early-stage CKD patients (stages I-III). Data are lacking on the association of high LDL cholesterol, high TG, and low HDL cholesterol levels with the progression of CKD in pre-dialysis patients (stages IV-V). Furthermore, trials investigating the effect of statins on disease progression, either defined by increasing proteinuria levels or renal function decline, are scarce and show contradictory results in pre-dialysis patients $[12,22]$. Therefore, we investigated the association of abnormal lipid levels (high LDL cholesterol, high TG, and low HDL cholesterol) with renal function decline in incident patients receiving specialized pre-dialysis care (CKD stages IV-V).

\section{Methods}

\section{Study Design}

The PREdialysis PAtient REcord-2 (PREPARE-2) study is a prospective follow-up study of incident pre-dialysis patients treated in one of the 25 participating nephrology outpatient clinics in the Netherlands. Patients were included between July 2004 and June 2011 at the start of specialized pre-dialysis care. They were treated by their nephrologists in their regular scheme according to the treatment guidelines of the Dutch Federation of Nephrology [23], guidelines partly based on the K/DOQI and KDIGO guidelines [24, 25]. At the start of specialized pre-dialysis care and in subsequent 6-month intervals, clinical data were collected. Patients were followed until the start of dialysis, receiving a kidney transplant, death, or censoring. Censoring was defined as: moving to an outpatient clinic not participating in the PREPARE-2 study, recovery of kidney function, refusal of further study participation, loss to follow-up, or August 1, 2012 (end of follow-up), whichever came first. The study was approved by the Medical Ethics Committee or Institutional Review Board (as appropriate) of all participating centres. 


\section{Patients}

To be eligible for inclusion in the PREPARE- 2 study, patients had to be at least 18 years of age. If possible, the inclusion should take place at the moment of referral to a specialized pre-dialysis outpatient clinic. In practice, this refers to incident pre-dialysis patients with an estimated glomerular filtration rate (eGFR) of $<20-30 \mathrm{ml} / \mathrm{min} / 1.73 \mathrm{~m}^{2}$, in whom renal function loss is progressive. Patients with a failing kidney transplant were also included in the study if the transplantation had taken place at least 1 year ago. All participants gave their written informed consent prior to study inclusion.

\section{Data Collection}

Data on demography, biometry, primary kidney disease, co-morbidities, medication use, and health-related quality of life were collected at the start of specialized pre-dialysis care and in subsequent 6-month intervals. Corresponding laboratory data were extracted from the electronic hospital information systems or medical records. Primary kidney disease was classified according to the codes of the European Renal Association-European Dialysis and Transplantation Association [26].

\section{Measurements and Definitions}

GFR was estimated using the 4-variable Modification of Diet in Renal Disease (MDRD) formula [27]. TG and HDL cholesterol levels (given in mmol/l) were directly measured according to the standard procedure in each participating outpatient clinic. LDL cholesterol (given in mmol/l) was either directly measured or estimated with the Friedewald equation: total cholesterol - HDL cholesterol - TG/2.2 [28].

\section{Outcome}

The primary outcome of our study was renal function decline. For the calculation of this decline, all individual eGFR measurements during the first 2 years of pre-dialysis care were used. Complete follow-up data were not used because the healthy and stable patients, who are still on pre-dialysis care after 2 years, would then provide a relatively large contribution to the overall renal function decline, possibly leading to a dilution of the estimated decline.

\section{Statistical Analyses}

For our statistical analyses, we only included those patients with at least one LDL cholesterol, TG, HDL cholesterol, and eGFR measurement during the first 2 years of pre-dialysis care $(\mathrm{n}=306)$. Baseline characteristics were presented as mean \pm SD for normally distributed continuous variables and as median (boundaries of interquartile range, IQR) for skewed continuous variables. LDL cholesterol, TG, and HDL cholesterol levels were used as determinants. All determinants were analyzed in categories based on the target goals recommended by the Dutch [23] and international [24, 29] pre-dialysis guidelines. The targets were $<2.50$ $\mathrm{mmol} / \mathrm{l}$ for LDL cholesterol, $<2.25 \mathrm{mmol} / \mathrm{l}$ for TG, and $\geq 1.00 \mathrm{mmol} / \mathrm{l}$ for HDL cholesterol. Two additional analyses were performed: (1) HDL cholesterol relative to LDL cholesterol (HDL/ LDL cholesterol ratio: $1 / 2.50 \mathrm{mmol} / \mathrm{l}=0.4$; target $\geq 0.4$ ) because HDL levels can be influenced by LDL levels, and (2) the number of targets that are not reached (1; not reaching 1 of the targets, 2; not reaching 2 of the targets, and 3; reaching none of the targets) to estimate the combined effect of lipid levels.

To associate these lipid levels with renal function decline, we used a linear mixed model. This model takes into account a correlation between individual repeated eGFR measurements and the deviation of the individual slopes from the mean slope [30]. All lipid levels and eGFR measurements during the first 2 years of pre-dialysis care were included in the model. The covariates included in the model were time (random), lipid levels, and time $\times$ lipid levels 
Table 1. Baseline patient characteristics for the total population and stratified by the LDL cholesterol target goal

\begin{tabular}{|c|c|c|c|}
\hline & \multirow{2}{*}{$\begin{array}{l}\text { Total } \\
(n=306)\end{array}$} & \multicolumn{2}{|c|}{ LDL cholesterol (2.50 mmol/l) } \\
\hline & & $\begin{array}{l}\text { below the target } \\
(\mathrm{n}=100)^{\mathrm{a}}\end{array}$ & $\begin{array}{l}\text { above the target } \\
(\mathrm{n}=97)^{\mathrm{a}}\end{array}$ \\
\hline Age, years & $69(56-76)$ & $70(60-78)$ & $67(55-75)$ \\
\hline Male, \% & 70 & 73 & 62 \\
\hline Smokers/quitters $<1$ year before inclusion, $\%$ & 26 & 26 & 27 \\
\hline \multicolumn{4}{|l|}{ Primary kidney disease, \% } \\
\hline Diabetes mellitus & 15 & 18 & 10 \\
\hline Glomerulonephritis & 12 & 11 & 10 \\
\hline Renal vascular disease & 32 & 36 & 27 \\
\hline Other & 41 & 35 & 53 \\
\hline $\mathrm{eGFR}^{\mathrm{b}}(\mathrm{n}=286), \mathrm{ml} / \mathrm{min} / 1.73 \mathrm{~m}^{2}$ & $16.7 \pm 6.1$ & $15.9 \pm 6.1$ & $16.5 \pm 5.8$ \\
\hline Proteinuria $(\mathrm{n}=178), \mathrm{g} / 24 \mathrm{~h}$ & $1.1(0.3-2.2)$ & $1.2(0.4-2.3)$ & $1.0(0.3-2.2)$ \\
\hline Systolic blood pressure $(n=304), \mathrm{mm} \mathrm{Hg}$ & $143 \pm 22$ & $142 \pm 20$ & $146 \pm 23$ \\
\hline Hemoglobin $(n=288), g / d l$ & $12.3 \pm 1.4$ & $12.3 \pm 1.4$ & $12.3 \pm 1.4$ \\
\hline Cardiovascular disease $^{c}, \%$ & 43 & 46 & 37 \\
\hline Diabetes mellitus ${ }^{\mathrm{d}}, \%$ & 27 & 37 & 17 \\
\hline
\end{tabular}

Values are given as medians (boundaries of IQR) for age and proteinuria and as means \pm SD for all other normally distributed continuous variables.

${ }^{a}$ Before multiple imputation, LDL cholesterol levels were available for 197 patients. ${ }^{\mathrm{b}}$ eGFR is calculated with the 4-variable MDRD formula. ${ }^{\mathrm{c}}$ Defined as the presence of a cerebrovascular accident, vascular problems, angina pectoris, myocardial infarction, or decompensatio cordis. ${ }^{\mathrm{d}}$ Present as primary kidney disease or co-morbidity.

(interaction term; to assess the difference in renal function decline between the lipid level categories). All analyses were adjusted for the potential baseline confounders age, sex, primary kidney disease, smoking status, cardiovascular disease, diabetes mellitus, body mass index, systolic blood pressure, and proteinuria. In an additional model, we further adjusted for available malnutrition-inflammation complex system-related factors (albumin, C-reactive protein, and subjective global assessment). To maintain power and avoid bias, missing baseline confounder values were imputed (using 10 repetitions) with the method of multiple imputations in PASW/SPSS version 20.0. This is a recommended technique where missing data for a patient are imputed by a value that is predicted by other known characteristics of this patient [31, 32]. All characteristics in tables 1 and 2, follow-up time, and the outcome (dialysis, transplantation, death, or censoring) were included in the imputation model, because missing baseline characteristics are often related to the outcome [33]. For each baseline characteristic, the number of patients with an available value is given in tables 1 and 2. Skewed distributed continuous variables, including follow-up time, were logarithmically transformed before being entered into the model.

We performed several additional analyses. First, we excluded patients who were prescribed lipid-lowering medication, defined as either a statin, a fibrate, or a cholesterol absorption inhibitor. Second, we analyzed the abnormal lipid levels continuously to investigate whether there was a similar association throughout the entire range of lipid levels. Third, we compared the effect of LDL cholesterol levels on renal function decline between the centres who estimated LDL cholesterol levels with the Friedewald equation and the centres who directly measured LDL cholesterol. Fourth, we excluded eGFR values measured in the 2 weeks before starting dialysis, receiving a kidney transplant, death, or censoring, because 
Table 2. Baseline lipid levels, treatment, and malnutrition-inflammation characteristics for the total population and stratified by the LDL cholesterol target goal

\begin{tabular}{|c|c|c|c|}
\hline & \multirow{2}{*}{$\begin{array}{l}\text { Total } \\
(n=306)\end{array}$} & \multicolumn{2}{|c|}{ LDL cholesterol (2.50 mmol/l) } \\
\hline & & $\begin{array}{l}\text { below the target } \\
(n=100)^{a}\end{array}$ & $\begin{array}{l}\text { above the target } \\
(\mathrm{n}=97)^{\mathrm{a}}\end{array}$ \\
\hline LDL cholesterol ${ }^{\mathrm{a},} \mathrm{mmol} / \mathrm{l}$ & $2.5 \pm 0.9$ & $1.8 \pm 0.5$ & $3.2 \pm 0.7$ \\
\hline $\mathrm{TG}(\mathrm{n}=206), \mathrm{mmol} / \mathrm{l}$ & $1.8 \pm 1.1$ & $1.7 \pm 0.9$ & $1.9 \pm 0.8$ \\
\hline HDL cholesterol $(\mathrm{n}=203), \mathrm{mmol} / \mathrm{l}$ & $1.3 \pm 0.4$ & $1.2 \pm 0.4$ & $1.4 \pm 0.5$ \\
\hline Lipid-lowering medication $(\mathrm{n}=270)^{\mathrm{b}}, \%$ & 17 & 17 & 19 \\
\hline Body mass index $(n=303)$ & $26.4 \pm 4.8$ & $26.9 \pm 5.1$ & $25.9 \pm 4.7$ \\
\hline Albumin $(\mathrm{n}=270), \mathrm{g} / \mathrm{l}$ & $41.0 \pm 4.5$ & $40.6 \pm 4.7$ & $42.0 \pm 4.0$ \\
\hline C-reactive protein $(n=178), \mathrm{mg} / \mathrm{l}$ & $4.2(3.0-10.0)$ & $4.5(1.9-13.3)$ & $4.0(3.0-8.0)$ \\
\hline \multicolumn{4}{|l|}{ Subjective global assessment $(n=232)^{c}, \%$} \\
\hline Well nourished & 88 & 89 & 90 \\
\hline Moderately well nourished & 12 & 11 & 10 \\
\hline Severely malnourished & 0 & 0 & 0 \\
\hline
\end{tabular}

Values are given as medians (boundaries of IQR) for C-reactive protein and as means \pm SD for all other normally distributed continuous variables.

${ }^{a}$ Before multiple imputation, LDL cholesterol levels were available for 197 patients. ${ }^{b}$ Defined as the prescription of statins, fibrates, and cholesterol absorption inhibitors. ${ }^{c}$ Defined as well nourished [subjective global assessment (SGA) 6-7], moderately well nourished (SGA 3-5), and severely malnourished (SGA 1-2).

there can be a large variation between eGFR measurements during this period. Fifth, we repeated all analyses after excluding the patients with only one eGFR measurement, to check whether the results from our linear mixed model were robust. Finally, we stratified our results by sex, because female hormones could influence the association between lipid levels and renal function decline [34]. p values $<0.05$ were considered statistically significant. Data were analyzed with PASW/SPSS version 20.0.

\section{Results}

\section{Baseline Characteristics}

Of the 502 patients, 306 patients had at least one LDL cholesterol, TG, HDL cholesterol, and eGFR measurement during the first 2 years of follow-up. These 306 patients were included in our statistical analyses and the known baseline characteristics of these patients (table 1) were very similar to the baseline characteristics of the 196 patients excluded. The median age of the population was 69 years (IQR 56-76) and 70\% were male. Mean eGFR \pm SD was $16.7 \pm$ $6.1 \mathrm{ml} / \mathrm{min} / 1.73 \mathrm{~m}^{2}$ and median proteinuria was $1.1 \mathrm{~g} / 24 \mathrm{~h}$ (IQR $0.3-2.2$ ). Stratification by the LDL cholesterol target goal $(<2.50 \mathrm{mmol} / \mathrm{l})$ revealed that patients above the target were slightly younger, less often male, had a slightly higher eGFR, higher systolic blood pressure, and had less often diabetes mellitus and cardiovascular disease (as primary kidney disease or co-morbidity) than patients below the target.

At the start of pre-dialysis care, $17 \%$ of the patients were treated with lipid-lowering medication (including statins, fibrates, and cholesterol absorption inhibitors; table 2). Of the patients with LDL cholesterol levels above the target goal ( $\geq 2.50 \mathrm{mmol} / \mathrm{l})$, only $19 \%$ were prescribed lipid-lowering medication. For patients with TG levels above the target goal ( $\geq 2.25 \mathrm{mmol} / \mathrm{l}$ ), this percentage was $23 \%$. After 6 months of follow-up, these percentages 
Table 3. Association of lipid levels with renal function decline

\begin{tabular}{|c|c|c|c|c|c|}
\hline & \multirow{2}{*}{$\begin{array}{l}\text { Measure- } \\
\text { ments, \% }\end{array}$} & \multicolumn{4}{|c|}{ Additional renal function decline $(95 \% \mathrm{CI})$} \\
\hline & & crude & Model $1^{c}$ & Model $2^{c}$ & Model $3^{c}$ \\
\hline \multicolumn{6}{|c|}{ LDL cholesterol, mmol/l } \\
\hline$<2.50$ & 60 & $\operatorname{ref}^{b}$ & ref & ref & ref \\
\hline$\geq 2.50$ & 40 & $0.10(0.00 \text { to } 0.20)^{*}$ & $0.11(0.01 \text { to } 0.21)^{*}$ & $0.11(0.01 \text { to } 0.21)^{*}$ & $0.11(0.01 \text { to } 0.21)^{*}$ \\
\hline \multicolumn{6}{|c|}{$T G, \mathrm{mmol} / \mathrm{l}$} \\
\hline$<2.25$ & 74 & $\mathrm{ref}^{\mathrm{b}}$ & ref & ref & ref \\
\hline$\geq 2.25$ & 26 & $0.05(-0.06$ to 0.16$)$ & $0.06(-0.05$ to 0.17$)$ & $0.06(-0.05$ to 0.17$)$ & $0.06(-0.05$ to 0.17$)$ \\
\hline \multicolumn{6}{|c|}{ HDL cholesterol, $\mathrm{mmol} / \mathrm{l}$} \\
\hline$<1.00$ & 71 & $-0.06(-0.17$ to 0.04$)$ & $-0.07(-0.17$ to 0.03$)$ & $-0.07(-0.18$ to 0.03$)$ & $-0.07(-0.18$ to 0.03$)$ \\
\hline$\geq 1.00$ & 29 & $\mathrm{ref}^{\mathrm{b}}$ & ref & ref & ref \\
\hline \multicolumn{6}{|c|}{$H D L / L D L$ cholesterol ratio } \\
\hline$<0.40$ & 27 & $0.06(-0.05$ to 0.18$)$ & $0.07(-0.05$ to 0.18$)$ & $0.07(-0.04$ to 0.18$)$ & $0.07(-0.04$ to 0.18$)$ \\
\hline$\geq 0.40$ & 73 & ref $^{b}$ & ref & ref & ref \\
\hline \multicolumn{6}{|c|}{ Targets not reacheda } \\
\hline 1 & 53 & $\operatorname{ref}^{b}$ & ref & ref & ref \\
\hline 2 & 32 & $-0.03(-0.19$ to 0.13$)$ & $-0.02(-0.18$ to 0.14$)$ & $-0.02(-0.18$ to 0.13$)$ & $-0.03(-0.18$ to 0.13$)$ \\
\hline 3 & 15 & $0.04(-0.15$ to 0.22$)$ & $0.04(-0.15$ to 0.22$)$ & $0.04(-0.15$ to 0.22$)$ & $0.04(-0.15$ to 0.22$)$ \\
\hline
\end{tabular}

The additional decline in renal function with its $95 \% \mathrm{CI}$ is given for the lipid level category not reaching the recommended target goal (LDL cholesterol $\geq 2.50 \mathrm{mmol} / \mathrm{l}, \mathrm{TG} \geq 2.25 \mathrm{mmol} / \mathrm{l}$, and HDL cholesterol $<1.00 \mathrm{mmol} / \mathrm{l}$ ) compared to the reference category (reaching the recommended target goal). The decline was assessed with a linear mixed model. A positive number indicates an additional decline in renal function.

a Including the targets for LDL cholesterol, TG, and the HDL/LDL cholesterol ratio, excluding patients reaching all targets. ${ }^{b}$ The crude mean $(95 \% \mathrm{CI})$ renal function decline in patients reaching the recommended target goals was $0.11 \mathrm{ml} / \mathrm{min} / 1.73 \mathrm{~m}^{2} /$ month $(0.04-0.18)$ for LDL cholesterol, $0.15 \mathrm{ml} / \mathrm{min} / 1.73 \mathrm{~m}^{2} /$ month $(0.09-0.22)$ for $\mathrm{TG}, 0.17 \mathrm{ml} / \mathrm{min} / 1.73 \mathrm{~m}^{2} / \mathrm{month}(0.11-0.24)$ for HDL cholesterol, $0.14 \mathrm{ml} / \mathrm{min} / 1.73 \mathrm{~m}^{2} / \mathrm{month}(0.07$ to 0.20$)$ for the HDL/LDL cholesterol ratio, and $0.16 \mathrm{ml} / \mathrm{min} / 1.73 \mathrm{~m}^{2} /$ month $(0.06-0.26)$ for reaching only 1 of the targets. ${ }^{c}$ Model 1: adjusted for sex and age; Model 2: additionally adjusted for primary kidney disease, smoking, cardiovascular disease, diabetes mellitus, body mass index, systolic blood pressure, and proteinuria; Model 3: additionally adjusted for albumin, C-reactive protein, and subjective global assessment. * $\mathrm{p}<0.05$.

slightly increased to 21 and 26\%, respectively. After stratification by the LDL cholesterol target goal $(<2.50 \mathrm{mmol} / \mathrm{l})$, malnutrition/inflammation markers - such as serum albumin and C-reactive protein - were similar between patients below and above the target.

\section{Renal Function Decline}

The overall renal function decline for all 306 patients was $0.19 \mathrm{ml} / \mathrm{min} / 1.73 \mathrm{~m}^{2} /$ month (95\% CI 0.14-0.23). The median number of eGFR measurements during the first 2 years of follow-up was 3 (IQR 2-4) and 8, 33 and $59 \%$ of these patients had 1, 2 and $\geq 3$ measurements, respectively. Patients with LDL cholesterol levels above the target goal of $2.50 \mathrm{mmol} / \mathrm{l}$ experienced an additional renal function decline (crude: $0.10 \mathrm{ml} / \mathrm{min} / 1.73 \mathrm{~m}^{2} / \mathrm{month}, 95 \% \mathrm{CI}$ $0.00-0.20 ; \mathrm{p}<0.05$ ) compared to patients with levels below the target (mean decline: 0.11 $\mathrm{ml} / \mathrm{min} / 1.73 \mathrm{~m}^{2} /$ month; table 3 and fig. 1 a). A similar trend (crude: $0.05 \mathrm{ml} / \mathrm{min} / 1.73 \mathrm{~m}^{2}$ / month, $95 \%$ CI -0.06 to 0.16 ) was found for patients with TG levels above the target goal of $2.25 \mathrm{mmol} / \mathrm{l}$ (mean decline: $0.15 \mathrm{ml} / \mathrm{min} / 1.73 \mathrm{~m}^{2} /$ month in patients with levels below the target; table 3 and fig. 1b). For HDL cholesterol levels, the association was reversed (not significant), meaning that patients with HDL cholesterol levels below the target goal of 1.00 $\mathrm{mmol} / \mathrm{l}$ experienced a slower renal function decline (crude: $-0.06 \mathrm{ml} / \mathrm{min} / 1.73 \mathrm{~m}^{2} / \mathrm{month}$, 


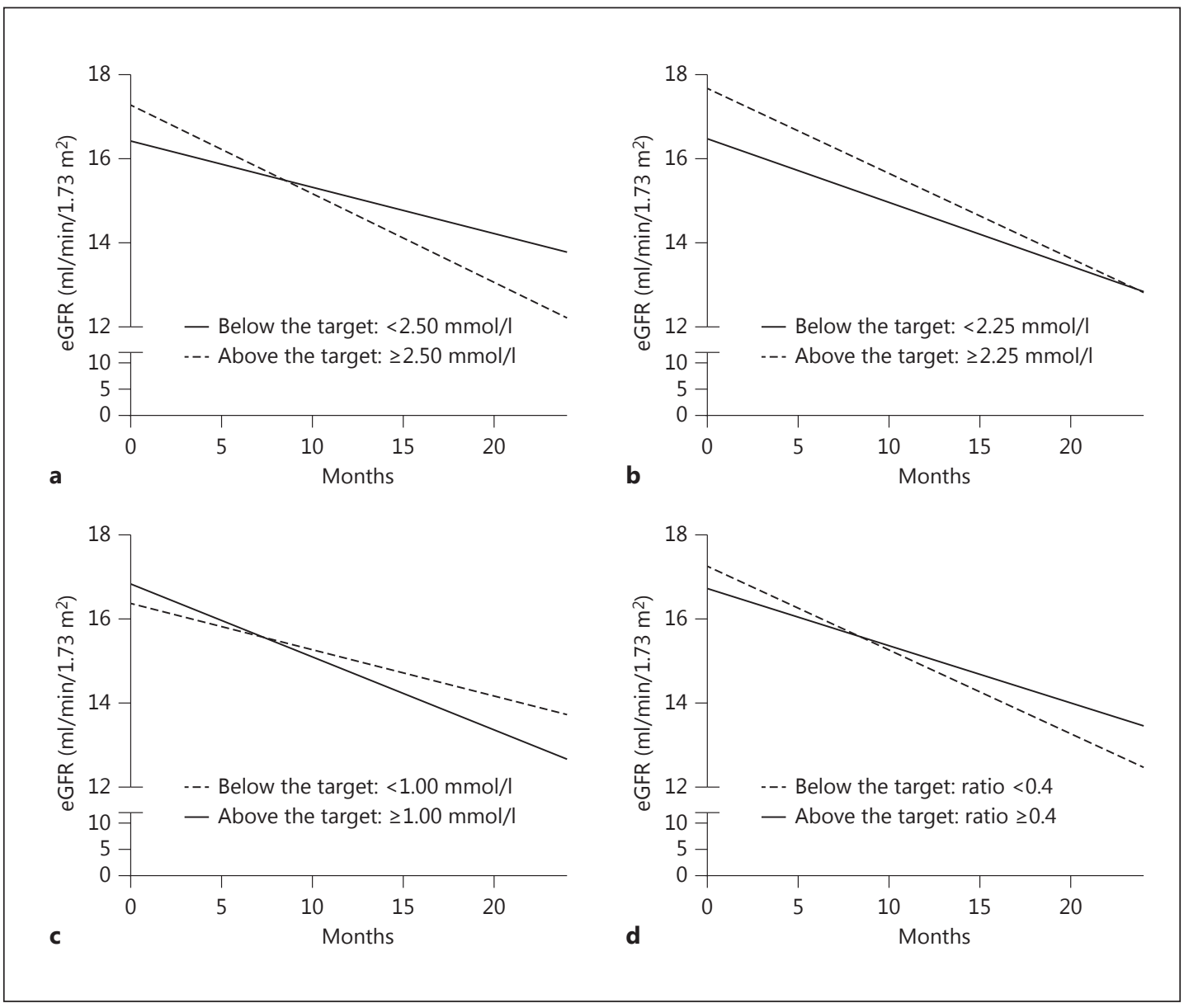

Fig. 1. Association of lipid levels with renal function decline. The lines represent the crude renal function decline for patients achieving and those not achieving the recommended target goal for LDL cholesterol levels (a), TG levels (b), HDL cholesterol levels (c), and the HDL/LDL cholesterol ratio (d). These intercepts and slopes were estimated with a linear mixed model.

95\% CI -0.17 to 0.04 ) compared to patients with levels above the target (mean decline: 0.17 $\mathrm{ml} / \mathrm{min} / 1.73 \mathrm{~m}^{2} /$ month, table 3 and fig. 1c). However, when we analyzed HDL cholesterol levels as a ratio of LDL cholesterol levels $(1.00 / 2.50 \mathrm{mmol} / \mathrm{l}=0.4)$, we again found a trend towards a faster renal function decline in patients with a ratio $<0.4$ (crude: $0.06 \mathrm{ml} / \mathrm{min} / 1.73$ $\mathrm{m}^{2} /$ month, $95 \% \mathrm{CI}-0.05$ to 0.18 ) compared to patients with a ratio $\geq 0.4$ (mean decline: 0.14 $\mathrm{ml} / \mathrm{min} / 1.73 \mathrm{~m}^{2} /$ month; table 3 and fig. $1 \mathrm{~d}$ ). Adjustment for potential confounders did not change the results substantially (table 3). Analyzing the number of targets not reached (including LDL cholesterol, TG, and HDL/LDL cholesterol ratio, range: 1-3) showed no additional decline when 2 or 3 targets, instead of only 1 target, were not reached.

\section{Additional Analyses}

LDL cholesterol levels above the target goal of $2.50 \mathrm{mmol} / \mathrm{l}$ remained associated with an accelerated renal function decline after excluding patients who were prescribed lipidlowering medication at any moment during follow-up ( $n=224$ included in the analysis, additional decline: $0.14 \mathrm{ml} / \mathrm{min} / 1.73 \mathrm{~m}^{2} /$ month, $95 \%$ CI $0.03-0.24$, Model 3 adjusted). The association of LDL cholesterol levels with renal function decline was comparable between 
patients included from centres that estimated $(n=91)$ and those that directly measured $(n=$ 215) LDL cholesterol (additional decline: $0.12 \mathrm{ml} / \mathrm{min} / 1.73 \mathrm{~m}^{2} / \mathrm{month}, 95 \% \mathrm{CI}-0.04$ to 0.27 , Model 3 adjusted, and additional decline: $0.07 \mathrm{ml} / \mathrm{min} / 1.73 \mathrm{~m}^{2} / \mathrm{month}, 95 \% \mathrm{CI}-0.05$ to 0.19 , Model 3 adjusted, respectively). Analyzing LDL cholesterol levels continuously resulted in an adjusted additional renal function decline of $0.06 \mathrm{ml} / \mathrm{min} / 1.73 \mathrm{~m}^{2} /$ month $(95 \% \mathrm{CI} 0.01-0.11$, Model 3 adjusted) per each $1 \mathrm{mmol} / \mathrm{l}$ increase. For TG levels and the HDL/LDL cholesterol ratio, the trend remained present but did not reach statistical significance. Excluding eGFR values measured in the 2 weeks before reaching an endpoint (starting dialysis, receiving a kidney transplant, death, or censoring) or excluding patients with only one eGFR measurement ( $\mathrm{n}=281$ included in the analysis) resulted in very similar results. In men and women, associations of LDL and HDL cholesterol levels with renal function decline were in the same direction, but they were only significant in women.

\section{Discussion}

In our cohort of incident patients receiving pre-dialysis care, an accelerated renal function decline was present in patients with LDL cholesterol levels above compared to those with levels below the target goal $(<2.50 \mathrm{mmol} / \mathrm{l})$, independent of the prescription of lipid-lowering medication. For TG levels above the target goal ( $\geq 2.25 \mathrm{mmol} / \mathrm{l})$ and a HDL/LDL cholesterol ratio $<0.4$, a trend was present, which did not reach statistical significance. Furthermore, at the start of pre-dialysis care, lipid-lowering medication was only prescribed to $19 \%$ of the patients with LDL cholesterol levels above the target goal and $23 \%$ of the patients with TG levels above the target goal.

Our observation that abnormal lipid levels were associated with an accelerated renal function decline is in line with studies performed in patients with early to moderate stages of CKD (stages I-IV) [17-21]. Moreover, we found that especially high LDL cholesterol levels were associated with an accelerated renal function decline. Our results may therefore suggest that statins (possibly combined with cholesterol absorption inhibitors), which mainly lower LDL cholesterol levels, are potentially effective medications to slow down renal function decline. However, statin trials have shown contradictory effects on renal function decline in pre-dialysis patients $[22,35,36]$. We have to keep in mind that these trials rarely included patients with advanced stages of CKD (IV-V). Only in the SHARP trial [12], more than half of the included pre-dialysis patients had CKD stages IV-V $(3,786$ out of 6,247$)$. This trial showed no statistical effect on the combined endpoint of reaching end-stage renal disease, defined as starting dialysis or receiving a kidney transplant, or the doubling of serum creatinine. However, the effect was strongest on doubling of serum creatinine (risk ratio 0.93, 95\% CI 0.86-1.01), which mostly resembles our outcome measure of renal function decline. Unfortunately, our study was underpowered to investigate the course of renal function decline in patients who were prescribed lipid-lowering medication $(n=52)$.

Furthermore, we found a low percentage of patients who were prescribed lipid-lowering medication (17\%), which is in line with other studies performed in pre-dialysis patients [37] and in patients receiving hemodialysis [38]. In addition, a striking finding in our cohort is that only $19 \%$ of the patients with LDL cholesterol levels above the target goal ( $\geq 2.50 \mathrm{mmol} / \mathrm{l})$ and $23 \%$ of the patients with TG levels above the target goal $(\geq 2.25 \mathrm{mmol} / \mathrm{l})$ were actually prescribed lipid-lowering medication at baseline. These percentages increased to 21 and $26 \%$, respectively, after 6 months of pre-dialysis care, but were still quite low. These findings are in line with the study by Mason et al. [38], showing that only $20.8 \%$ of the patients on hemodialysis with a total cholesterol level $\geq 5.17 \mathrm{mmol} / \mathrm{l}$, which resembles patients with LDL cholesterol and/or TG levels above the target goal, were actually treated with statins. An 
explanation for this low percentage in patients receiving pre-dialysis care and dialysis treatment could be that physicians are not convinced that the prescription of lipid-lowering medication is beneficial in these patients. For example, it may have been unclear for physicians whether patients with abnormal lipid levels, but without an additional cardiovascular risk factor (e.g. a history of diabetes mellitus or cardiovascular disease), should be treated with lipid-lowering medication. Our findings indeed showed a low prevalence of these comorbidities in patients with LDL cholesterol levels above the target goal of $2.50 \mathrm{mmol} / \mathrm{l}$. On the other hand, a subgroup analysis in the SHARP trial suggests that lipid-lowering medication is beneficial for patients without diabetes mellitus or cardiovascular disease, leading to less major cardiovascular events (composite endpoint: non-fatal myocardial infarction or any cardiac death, any stroke, or any arterial revascularization excluding dialysis access procedures). This evidence may have convinced physicians to prescribe lipid-lowering medication to these patients. However, the effect of lipid-lowering medication on renal function decline has not been elucidated yet. More trials in pre-dialysis patients that investigate this effect are needed but may not be justified to perform. The effect of lipid-lowering medication on the reduction of major cardiovascular events in pre-dialysis patients (CKD stages IV-V) is apparent and this evidence may be sufficient for prescribing these medications to these patients. Therefore, post-hoc subgroup analyses of published trials, meta-analyses and new prospective follow-up data should gain more information about the possible renoprotective effect of lipid-lowering medication.

The great strength of our study lies in its longitudinal character and the inclusion of incident patients. In this way, we could take into account lipid level variability and changes during pre-dialysis care. Furthermore, we could assess renal function decline, which is a more detailed outcome measure compared to the robust measures used in for example the SHARP trial (starting end-stage renal disease or doubling of serum creatinine). A disadvantage of our study is the presence of missing data. Lipid levels were not routinely measured at each predialysis care visit. These missing data resulted in the exclusion of 39\% of the patients $(196$ out of 502). Fortunately, baseline characteristics were very similar between the 306 patients included and the 196 patients excluded from our statistical analyses. Therefore, we could reasonably assume that the exclusion of patients with missing lipid levels did not bias our results. The last thing we have to keep in mind is that our study only included patients with an eGFR $<20-30 \mathrm{ml} / \mathrm{min} / 1.73 \mathrm{~m}^{2}$ who had been referred to one of our outpatient clinics for pre-dialysis care. Therefore, our results are not generalizable to all patients with CKD stages IV-V.

In conclusion, high levels of LDL cholesterol are associated with an accelerated renal function decline. Further research in the specific population of pre-dialysis patients is necessary to investigate whether lipid-lowering medication can slow down renal function decline.

\section{Acknowledgements}

The authors especially thank all patients who participated in the PREPARE- 2 study. The nursing staffs of the participating centres as well as the trial nurses and data managers from the Hans Mak Institute are gratefully acknowledged for collecting the clinical data. This study was supported by grants from the Dutch Kidney Foundation (SB 110) and an unrestricted grant from Amgen B.V. 
de Goeij et al.: Lipid Levels and Renal Function Decline in Pre-Dialysis Patients

\section{Disclosure Statement}

The authors have no involvements that might raise the question of bias in the work reported or in the conclusions, implications, or opinions stated. None of the sponsors were involved in the study design, collection of data, statistical analyses, interpretation of data, writing of the manuscript, or in the decision to submit the paper for publication. The results presented in this paper have not been published previously in whole or part, except in abstract format.

\section{References}

1 Kannel WB, Castelli WP, Gordon T: Cholesterol in the prediction of atherosclerotic disease. New perspectives based on the Framingham study. Ann Intern Med 1979;90:85-91.

-2 Pekkanen J, Linn S, Heiss G, Suchindran CM, Leon A, Rifkind BM, Tyroler HA: Ten-year mortality from cardiovascular disease in relation to cholesterol level among men with and without preexisting cardiovascular disease. N Engl J Med 1990;322:1700-1707.

-3 Cui Y, Blumenthal RS, Flaws JA, Whiteman MK, Langenberg P, Bachorik PS, Bush TL: Non-high-density lipoprotein cholesterol level as a predictor of cardiovascular disease mortality. Arch Intern Med 2001;161:14131419.

-4 Iseki K, Yamazato M, Tozawa M, Takishita S: Hypocholesterolemia is a significant predictor of death in a cohort of chronic hemodialysis patients. Kidney Int 2002;61:1887-1893.

-5 Kilpatrick RD, McAllister CJ, Kovesdy CP, Derose SF, Kopple JD, Kalantar-Zadeh K: Association between serum lipids and survival in hemodialysis patients and impact of race. J Am Soc Nephrol 2007;18:293-303.

-6 Liu Y, Coresh J, Eustace JA, Longenecker JC, Jaar B, Fink NE, Tracy RP, Powe NR, Klag MJ: Association between cholesterol level and mortality in dialysis patients: role of inflammation and malnutrition. JAMA 2004;291: 451-459.

7 Kovesdy CP, Anderson JE, Kalantar-Zadeh K: Inverse association between lipid levels and mortality in men with chronic kidney disease who are not yet on dialysis: effects of case mix and the malnutrition-inflammation-cachexia syndrome. J Am Soc Nephrol 2007;18:304-311.

8 Chawla V, Greene T, Beck GJ, Kusek JW, Collins AJ, Sarnak MJ, Menon V: Hyperlipidemia and long-term outcomes in nondiabetic chronic kidney disease. Clin J Am Soc Nephrol 2010;5:1582-1587.

-9 Shlipak MG, Fried LF, Cushman M, Manolio TA, Peterson D, Stehman-Breen C, Bleyer A, Newman A, Siscovick D, Psaty B: Cardiovascular mortality risk in chronic kidney disease: comparison of traditional and novel risk factors. JAMA 2005;293:1737-1745.

10 Ettinger WH Jr, Harris T, Verdery RB, Tracy R, Kouba E: Evidence for inflammation as a cause of hypocholesterolemia in older people. J Am Geriatr Soc 1995;43:264-266.

-11 Ettinger WH Jr, Sun WH, Binkley N, Kouba E, Ershler W: Interleukin-6 causes hypocholesterolemia in middleaged and old rhesus monkeys. J Gerontol A Biol Sci Med Sci 1995;50:M137-M140.

12 Baigent C, Landray MJ, Reith C, et al: The effects of lowering LDL cholesterol with simvastatin plus ezetimibe in patients with chronic kidney disease (Study of Heart and Renal Protection): a randomised placebocontrolled trial. Lancet 2011;377:2181-2192.

13 Fox CS, Larson MG, Leip EP, Culleton B, Wilson PW, Levy D: Predictors of new-onset kidney disease in a community-based population. JAMA 2004;291:844-850.

14 Muntner P, Coresh J, Smith JC, Eckfeldt J, Klag MJ: Plasma lipids and risk of developing renal dysfunction: the atherosclerosis risk in communities study. Kidney Int 2000;58:293-301.

15 Obermayr RP, Temml C, Knechtelsdorfer M, Gutjahr G, Kletzmayr J, Heiss S, Ponholzer A, Madersbacher S, Oberbauer R, Klauser-Braun R: Predictors of new-onset decline in kidney function in a general middleeuropean population. Nephrol Dial Transplant 2008;23:1265-1273.

16 Schaeffner ES, Kurth T, Curhan GC, Glynn RJ, Rexrode KM, Baigent C, Buring JE, Gaziano JM: Cholesterol and the risk of renal dysfunction in apparently healthy men. J Am Soc Nephrol 2003;14:2084-2091.

17 Hovind P, Rossing P, Tarnow L, Smidt UM, Parving HH: Progression of diabetic nephropathy. Kidney Int 2001; 59:702-709.

18 Hunsicker LG, Adler S, Caggiula A, England BK, Greene T, Kusek JW, Rogers NL, Teschan PE: Predictors of the progression of renal disease in the Modification of Diet in Renal Disease Study. Kidney Int 1997;51:19081919.

19 Ravid M, Brosh D, Ravid-Safran D, Levy Z, Rachmani R: Main risk factors for nephropathy in type 2 diabetes mellitus are plasma cholesterol levels, mean blood pressure, and hyperglycemia. Arch Intern Med 1998;158: 998-1004.

-20 Samuelsson O, Mulec H, Knight-Gibson C, Attman PO, Kron B, Larsson R, Weiss L, Wedel H, Alaupovic P: Lipoprotein abnormalities are associated with increased rate of progression of human chronic renal insufficiency. Nephrol Dial Transplant 1997;12:1908-1915. 
21 Washio M, Okuda S, Ikeda M, Hirakata H, Nanishi F, Onoyama K, Yoshimura T, Fujishima M: Hypercholesterolemia and the progression of the renal dysfunction in chronic renal failure patients. J Epidemiol 1996;6: 172-177.

22 Navaneethan SD, Pansini F, Perkovic V, Manno C, Pellegrini F, Johnson DW, Craig JC, Strippoli GF: HMG CoA reductase inhibitors (statins) for people with chronic kidney disease not requiring dialysis. Cochrane Database Syst Rev 2009;CD007784.

23 Dutch Federation of Nephrology: Multidisciplinary Guidelines Pre-Dialysis. Dutch Federation of Nephrology, 2011.

24 Kidney Disease: Improving Global Outcomes (KDIGO): Clinical Practice Guidelines. KDIGO, 2011.

-25 National Kidney Foundation: K/DOQI clinical practice guidelines for chronic kidney disease: evaluation, classification, and stratification. Am J Kidney Dis 2002;39:S1-S266.

26 European Renal Association/Dialysis and Transplantation Association (ERA/EDTA) registry: Annual report 2009. ERA/EDTA Registry, 2009.

27 Levey AS, Greene T, Kusek JW, Beck GJ; MDRD Study Group: A simplified equation to predict glomerular filtration rate from serum creatinine (abstract). J Am Soc Nephrol 2000;11:155A.

28 Friedewald WT, Levy RI, Fredrickson DS: Estimation of the concentration of low-density lipoprotein cholesterol in plasma, without use of the preparative ultracentrifuge. Clin Chem 1972;18:499-502.

-29 Kidney Disease Outcomes Quality Initiative (K/DOQI) Group: K/DOQI clinical practice guidelines for management of dyslipidemias in patients with kidney disease. Am J Kidney Dis 2003;41:S1-S91.

30 FitzMaurice GM, Laird NM, Ware JH: Applied Longitudinal Analysis. Hoboken, John Wiley \& Sons, 2011.

-31 van Buuren S, Boshuizen HC, Knook DL: Multiple imputation of missing blood pressure covariates in survival analysis. Stat Med 1999;18:681-694.

-32 Donders AR, van der Heijden GJ, Stijnen T, Moons KG: Review: a gentle introduction to imputation of missing values. J Clin Epidemiol 2006;59:1087-1091.

33 Moons KG, Donders RA, Stijnen T, Harrell FE Jr: Using the outcome for imputation of missing predictor values was preferred. J Clin Epidemiol 2006;59:1092-1101.

-34 Haffner SM, Valdez RA: Endogenous sex hormones: impact on lipids, lipoproteins, and insulin. Am J Med 1995; 98:40S-47S

35 Sandhu S, Wiebe N, Fried LF, Tonelli M: Statins for improving renal outcomes: a meta-analysis. J Am Soc Nephrol 2006;17:2006-2016.

-36 Strippoli GF, Navaneethan SD, Johnson DW, Perkovic V, Pellegrini F, Nicolucci A, Craig JC: Effects of statins in patients with chronic kidney disease: meta-analysis and meta-regression of randomised controlled trials. BMJ 2008;336:645-651.

37 Bailie GR, Eisele G, Liu L, Roys E, Kiser M, Finkelstein F, Wolfe R, Port F, Burrows-Hudson S, Saran R: Patterns of medication use in the RRI-CKD study: focus on medications with cardiovascular effects. Nephrol Dial Transplant 2005;20:1110-1115.

38 Mason NA, Bailie GR, Satayathum S, Bragg-Gresham JL, Akiba T, Akizawa T, Combe C, Rayner HC, Saito A, Gillespie BW, Young EW: HMG-coenzyme a reductase inhibitor use is associated with mortality reduction in hemodialysis patients. Am J Kidney Dis 2005;45:119-126. 